\title{
Asymptomatic Primary Hyperparathyroidism
}

\author{
Shonni J. Silverberg ${ }^{\star}$, Marcella D. Walker, and John P. Bilezikian \\ Division of Endocrinology, Department of Medicine, College of Physicians and Surgeons, \\ Columbia University, New York, NY, USA
}

\begin{abstract}
The clinical profile of primary hyperparathyroidism (PHPT) as it is seen in the United States and most Western countries has evolved significantly over the past half century. The introduction of the multichannel serum autoanalyzer in the 1970s led to the recognition of a cohort of individuals with asymptomatic hypercalcemia, in whom evaluation led to the diagnosis of PHPT. The term "asymptomatic primary hyperparathyroidism" was introduced to describe patients who lack obvious signs and symptoms referable to either excess calcium or parathyroid hormone. Although it was expected that asymptomatic patients would eventually develop classical symptoms of PHPT, observational data suggest that most patients do not evolve over time to become overtly symptomatic. In most parts of the world, the asymptomatic phenotype of PHPT has replaced classical PHPT. This report is a selective review of data on asymptomatic PHPT: its demographic features, presentation and natural history, as well as biochemical, skeletal, neuromuscular, psychological, and cardiovascular manifestations. In addition, we will summarize available information on treatment indications and options for those with asymptomatic disease.
\end{abstract}

\section{Keywords}

Asymptomatic primary hyperparathyroidism; normocalcemic primary hyperparathyroidism; parathyroidectomy

\section{Introduction}

The clinical profile of primary hyperparathyroidism (PHPT) as it is seen in the United States and most Western countries has evolved significantly over the past half century. Classical PHPT, the disorder described by Fuller Albright in the 1930s, was characterized by nephrolithiasis and nephrocalcinosis in over two-thirds of patients, and the prototypical skeletal abnormality of the hyperparathyroid state, osteitis fibrosa cystica, was seen in nearly one-third of the affected individuals (1). In addition, signs and symptoms affecting the psychiatric, neurologic, cardiovascular, and gastrointestinal systems were frequent concomitants of the disease.

\footnotetext{
(C) Copyright 2013 Published by Elsevier Inc. on behalf of The International Society for Clinical Densitometry

*Address correspondence to: Shonni J. Silverberg, MD, Department of Medicine, College of Physicians and Surgeons, Columbia University, PH 8W-864, 630 West 168th Street, New York, NY 10032. sjs5@ columbia.edu.

Disclosures: Dr John P. Bilezikian is a consultant for Amgen, Eli Lilly, Radius, NPS Pharmaceuticals, Merck, Warner Chilcott, and GSK and receives research support from NPS Pharmaceuticals and Amgen. No conflicts of interest reported for the remaining authors.
} 
The introduction of the multichannel serum autoanalyzer in the 1970s led to the recognition of a cohort of individuals with asymptomatic hypercalcemia, in whom evaluation led to the diagnosis of PHPT (2). The term "asymptomatic primary hyperparathyroidism" was introduced to describe patients who lack obvious signs and symptoms referable to either excess calcium or parathyroid hormone (PTH). In the decades that have passed since the original recognition of asymptomatic PHPT, a large body of research has emerged describing various features of the disease. These include demographic features, presentation and natural history, as well as biochemical, skeletal, neuromuscular, psychological, and cardiovascular manifestations. This report is a selective review of some of these data, as well as data about available information on treatment indications and options for those with asymptomatic disease.

\section{Diagnosis and Differential Diagnosis}

The biochemical hallmarks of PHPT include elevated serum calcium levels in the presence of elevated or inappropriately normal levels of PTH $(3,4)$. All nonparathyroid causes of hypercalcemia are associated with levels that are suppressed (5). Malignancy-associated hypercalcemia is the disorder to consider primarily in the differential diagnosis of PHPT. However, other than in multiple myeloma, hypercalcemia is generally a late finding in the clinical course of cancers, and patients are rarely asymptomatic. Although other causes of hypercalcemia may present in asymptomatic individuals, a PTH level should be measured early in the course of the diagnostic evaluation. It usually confirms the diagnosis.

In asymptomatic individuals, the differential diagnosis of hypercalcemia and abnormal PTH levels includes drug-associated PHPT, familial hypocalciuric hypercalcemia (FHH), as well as the rare patient with ectopic secretion of authentic PTH from a malignancy (although these individuals would not be expected to be asymptomatic) (5). Thiazide diuretics and lithium can lead to alterations in parathyroid function that mimic PHPT. The possibility of drug-induced hypercalcemia with high PTH levels can be investigated by withdrawal of the suspected medication for approx 3 mo, if this is medically safe, followed by retesting. In most instances, drug withdrawal does not change the biochemical findings, and the medication can be ruled out as a cause. The drug can then be reintroduced. FHH is diagnosed in patients with a family history of hypercalcemia, in whom recognition of elevated calcium levels begins at a relatively early age (6). Confirmation begins with measurement of calcium/creatinine excretion ratio of less than 0.01 on a normal calcium diet.

Advances in techniques to measure PTH such as immunoradiometric and immunochemiluminometric assays have facilitated the diagnosis of PHPT, but they have not eliminated all issues $(7,8)$. The most troublesome, at times, are those whose PTH level is technically normal, although any nonsuppressed PTH value should suggest a parathyroid etiology for hypercalcemia. The newer third-generation PTH assays, in which only $\mathrm{PTH}(1-$ 84 ) is measured, promised to yield clarity on this issue (9). However, these later-generation assays do not increase diagnostic sensitivity over second-generation assays in which circulating PTH fragments and the full-length molecule are measured (4). One of the most vexing situations is the patient whose PTH level is in the lower range of normal (e.g., 25 
$\mathrm{pg} / \mathrm{mL}$; normal range: $10-65 \mathrm{pg} / \mathrm{mL}$ ). When faced with a situation like this, most experts correctly regard detectable levels of PTH, albeit in the lower range of normal, to be inappropriately elevated in the setting of hypercalcemia.

\section{Clinical Presentation of Asymptomatic PHPT}

Asymptomatic PHPT is a disease that affects mainly women in their middle years. The disease occurs most commonly within the first decade of the menopause. Women outnumber men by approx 3:1. By definition, asymptomatic PHPT does not present with overt clinical signs. However, this does not mean that the hyperparathyroid process has not already affected traditional target organs known to be at risk in PHPT. A brief summary of findings in asymptomatic PHPT follows $(10,11)$.

Biochemical Profile-Hypercalcemia is mild in asymptomatic PHPT, generally within 1 $\mathrm{mg} / \mathrm{dL}$ of the upper limit of the normal range. The PTH level is also only modestly elevated, generally within 1.5-2-fold above the upper limit of normal. In asymptomatic disease, unlike classical PHPT, the serum phosphorus concentration is not usually low, and urinary calcium excretion is frankly elevated in only about one-third of patients. Vitamin D insufficiency (25-hydroxyvitamin D: 20-30 ng/mL) or deficiency (25-hydroxyvitamin D $<20 \mathrm{ng} / \mathrm{mL})$ is common $(12,13)$. Because of the effects of PTH to stimulate the conversion of 25-hydroxyvitamin D to 1,25-dihydroxyvitamin D, 1,25-dihydroxyvitamin D is often elevated (14). In some studies of more severe PHPT, vitamin D deficiency was reported to be more common than in the general population (13). Although it is unknown whether this is true for asymptomatic PHPT, it is clear that patients with mild PHPT and low vitamin D levels have more marked elevations in PTH levels than those who are replete.

Skeletal Profile-Osteitis fibrosa cystica, brown tumors of the long bones, and radiologic evidence of periosteal bone resorption were commonly seen in classical PHPT (1). Although these findings are not part of the profile of asymptomatic PHPT, bone densitometric and histomorphometric analyses clearly document skeletal involvement. By bone mineral density (BMD), the distal one-third radius, a cortical site, is generally reduced, whereas the lumbar spine, a more cancellous site, is generally preserved (15). The hip, which is intermediate in composition with substantial cortical and cancellous elements, also tends to be intermediate in BMD between the radius and lumbar spine sites. Reduction of cortical bone and preservation of cancellous bone in asymptomatic PHPT are elucidated more dramatically by histomorphometric studies $(16,17)$. Although most histomorphometric reports do not specifically exclude all patients with symptomatic disease, those focused on cohorts with very mild hypercalcemia confirm cortical thinning, with preservation of cancellous bone volume and connectivity of trabecular plates with advancing age. Consistent with the fact that PTH levels are higher in asymptomatic PHPT patients with coexisting vitamin D deficiency, histomorphometric analysis demonstrates worse cortical and improved cancellous indices in those with low 25-hydroxyvitamin D levels $(12,18)$.

The clinical sequelae associated with the densitometric and histomorphometric picture of bone in patients with asymptomatic PHPT might be expected to be a reduction in fracture risk in cancellous bone and increased risk of fracture in cortical bone. The data on fracture 
incidence in PHPT in general are fraught with significant discrepancies in outcomes (1926). Data specifically addressing the question of subsequent fracture risk in patients who have asymptomatic PHPT at the time of presentation are extremely sparse. Fracture studies include cases that date back to a time when PHPT was unlikely to be asymptomatic. For example, the largest fracture study, which found an increase in hip fracture in men but not in women among 1800 Swedish patients, reviewed data on patients beginning in 1965, when PHPT would likely have been symptomatic (21). Similarly, the Mayo experience also included subjects seen initially between 1965 and 1992 (23). Symptoms of PHPT are rarely addressed, and the extent of hypercalcemia was only occasionally considered as a possible risk for fracture. Asymptomatic disease is assessed per se in only 2 studies. In the first, a small study, vertebral fractures were not more common in asymptomatic PHPT (20). In the second, Vignali et al (24) assessed vertebral fractures as determined by dual-energy X-ray absorptiometry-based vertebral fracture assessment. In this case-control study, vertebral fractures were detected more frequently in subjects with PHPT (24.6\%) than in control subjects $(4.0 \% ; p<0.001)$. Asymptomatic PHPT patients made up $73 \%$ of their cohort of 150 subjects. When the asymptomatic subjects were considered separately, vertebral fractures remained more common than in control subjects, but the observed difference was driven by those who met 2002 National Institutes of Health (NIH) surgical guidelines. Fracture risk in asymptomatic patients not meeting indications for surgery was indistinguishable from control subjects. There are no specific data on hip and other nonvertebral fractures in asymptomatic PHPT patients.

Renal Profile-Again, by definition, patients with asymptomatic PHPT do not have nephrolithiasis. The incidence of hypercalciuria in asymptomatic PHPT is approx $30 \%$. As is the case in classical PHPT, the prevalence of nephrocalcinosis is unknown. Walker et al (27) have recently shown that in subjects whose creatinine clearance is $<60 \mathrm{cc} / \mathrm{min}$, there is no increase in PTH levels as compared with subjects with creatinine clearance $>60 \mathrm{cc} / \mathrm{min}$, but by histomorphometric analysis of bone biopsies, those with reduced renal function have evidence for greater bone resorption.

Neuromuscular Profile-The typical neuromuscular syndrome of classical PHPT was characterized by proximal muscle weakness and atrophy of type II muscle fibers (28). This is not seen in asymptomatic PHPT. Subjective complaints of weakness have also been investigated in an observational study of 42 patients with mild PHPT (29). Although generalized weakness and easy fatigability were common complaints, no patient had neuromuscular findings of muscle weakness or atrophy, hyperreflexia, abnormal gait, tongue fasciculations, or objective changes in mental status on neurological examination.

Psychiatric and Cognitive Profile-This area has given rise to the most significant controversies in the description of asymptomatic PHPT and is covered in greater detail in another report in this issue (30). Mental status changes, obtundation, and frank psychosis were reported in patients with severe hypercalcemia of classical PHPT. Although these signs are incompatible with the diagnosis of asymptomatic PHPT, neurocognitive and psychiatric complaints are common. These include easy fatigability, weakness, intellectual weariness, and mild depression. This has led some investigators to conclude that asymptomatic PHPT 
is extremely rare, as many patients have 1 or more of these nonspecific neuropsychological complaints. Although many patients note improvement in 1 or more of these symptoms after successful parathyroidectomy, it has been more challenging to prove a causal association.

Several studies have specifically addressed cognitive function in PHPT (31-36). Data interpretation has been limited by small sample sizes, issues with control populations, generalizations from narrow testing of cognitive domains, and variable follow-up periods. Furthermore, symptomatic PHPT patients were often included in the studies. One study found deficits in verbal memory and nonverbal abstraction compared with non-PHPT controls that improved after surgical cure (35). Importantly, the study controlled for IQ and symptoms of anxiety and depression. There is only 1 randomized controlled study of parathyroidectomy vs observation on cognition in asymptomatic PHPT (37). Perrier et al (37) found no cognitive effect of surgery, but they may have been limited in their ability to find results of significance by their small sample size $(\mathrm{N}=18)$.

More studies have focused on psychiatric symptoms and quality of life (38-44). Most were not specific to patients with asymptomatic disease, and interpretation of others has been limited by flaws in study design. It was hoped that definitive data would be provided by 3 randomized trials of surgery in asymptomatic PHPT (45-47). Using the 36-Item Short Form Health Survey (one also used the Comprehensive Psychopathological Rating Scale), all 3 found baseline abnormalities in patients with asymptomatic PHPT, with overall outcome slightly favoring surgery. However, the baseline abnormalities differed from study to study, and the indices that improved after surgery were not consistent either. These results suggest that no particular patient can anticipate a specific kind or extent of improvement after parathyroidectomy. The inconsistency of the findings, when considered together, led the most recent International Conference on Asymptomatic PHPT to omit neuropsychiatric symptoms as an indication for surgery. Furthermore, at this time, most experts do not regard the presence of these complaints to exclude categorizing such patients as asymptomatic.

Cardiovascular Profile-Cardiovascular manifestations of classical PHPT included hypertension; vascular, myocardial, and valvular calcifications; left ventricular hypertrophy; arrhythmia; and increased mortality from myocardial infarction and stroke. Data on asymptomatic PHPT are more limited. Cardiovascular mortality is increased in European cohorts with moderate hypercalcemia that are likely to include many symptomatic and asymptomatic patients $(48,49)$. Even the Mayo Clinic study in mild PHPT (mean serum calcium: $10.9 \mathrm{mg} / \mathrm{dL}$ ) did not specifically exclude symptomatic patients (50). They found a decrease in cardiovascular mortality (relative risk [RR]: 0.60 ; 95\% confidence interval: $0.45-0.79)$ in this group. Only 1 randomized clinical trial in asymptomatic PHPT has reported cardiovascular endpoints (51). In a 2-yr randomized trial of parathyroidectomy vs observation in 116 patients, mean arterial and diastolic blood pressures declined equally in those followed with and without surgery. Similarly, no differences were noted in lipids, adiponectin, leptin, or C-reactive protein. Recent observational data in very mild PHPT (mean serum calcium: $10.6 \mathrm{mg} / \mathrm{dL}$ ) have demonstrated increased aortic valve calcification area, increased aortic and carotid stiffness, as well as increased carotid intima-medial thickness, all preclinical predictors of deleterious cardiovascular outcomes (52-55). There was no evidence of left ventricular hypertrophy or diastolic dysfunction in these patients, 
and parathyroidectomy did not lead to improvement in the abnormalities in these uncontrolled studies (56).

Gastrointestinal Involvement-Pancreatitis and peptic ulcer disease were considered to be associated with classical PHPT. The former is virtually never seen as a consequence of the very mild hypercalcemia that occurs in asymptomatic PHPT (57). Peptic ulcer disease is occasionally seen in patients with asymptomatic PHPT, but it is felt that the association is chance rather than causal.

\section{Asymptomatic PHPT and Clinical Forms of PHPT}

Asymptomatic PHPT can overlap with some but not all clinical forms of PHPT. That is to say, patients with PHPT due to multiple endocrine neoplasia types I and II, familial PHPT not associated with other endocrine disorders, and familial cystic parathyroid adenomatosis may present with asymptomatic PHPT. On the other hand, "classical" PHPT is, by definition, symptomatic. Acute PHPT or "parathyroid crisis" and neonatal PHPT similarly do not present as asymptomatic PHPT (58).

Normocalcemic PHPT was first formally recognized as a specific clinical form of the disease at the most recent International Conference on Asymptomatic PHPT in $2008(4,10)$. Although most patients with normocalcemic PHPT are asymptomatic, this is not always the case. To make this particular diagnosis, patients must have normal serum total and ionized calcium concentrations with elevated PTH levels (the latter is not required in patients with hypercalcemic PHPT, in whom a PTH in the normal range is abnormal). Furthermore, alternate causes for secondary hyperparathyroidism must be sought and eliminated. Indeed, the most common clinical setting in which the cardinal biochemical findings of this disorder are seen (normal calcium, elevated PTH levels) is that of a patient with coexisting hypercalcemic PHPT and vitamin D deficiency. In these patients, vitamin D deficiency or insufficiency can lower serum calcium levels in hypercalcemic PHPT into the normal range. Other causes of secondary hyperparathyroidism that must be ruled out to diagnose normocalcemic PHPT include renal failure, significant hypercalciuria, and gastrointestinal causes of calcium malabsorption.

Normocalcemic PHPT is often diagnosed in individuals who are undergoing evaluation for low BMD or who are receiving comprehensive screening tests for their skeletal health. In some patients, this constellation of findings may represent the earliest manifestation of hypercalcemic PHPT, when PTH alone is elevated, and serum calcium is still normal. Little is known about the natural history of this phenotype. Some patients quickly progress to hypercalcemic disease, whereas others do not. It is also not known whether surgical criteria for hypercalcemic disease (see later section) apply to patients with normocalcemic disease. The subject of normocalcemic PHPT is considered separate elsewhere in this issue (59).

\section{Treatment and Natural History}

Surgery-Surgery remains the only curative option in asymptomatic, as in symptomatic disease. A discussion of surgical techniques is beyond the scope of this report but is covered elsewhere in this issue $(60,61)$. However, it is important to note that in asymptomatic PHPT, 
surgery is rarely complicated by postoperative hypocalcemia. Surgery leads to normalization of biochemical abnormalities. Increased bone density has been reported in short-term (1-2 yr) randomized clinical trial data and long-term uncontrolled observational studies (up to 15 yr) (41-43,62-64). The increase is seen earliest at the lumbar spine and hip but eventually also at the distal one-third radius. Recent data using high-resolution peripheral quantitative computed tomography further suggest that parathyroidectomy also improves bone geometry and microarchitecture in female patients with PHPT.

Although parathyroidectomy is indicated in all patients with overt clinical symptoms, there has been considerable controversy over the need to treat those patients who are diagnosed in the absence of clear symptomatology. This has led to the development of guidelines for surgery crafted by experts in the field, first under the auspices of the NIH and then in the context of an international consortium of experts and medical societies. Initial NIHassociated guidelines in 1990 were revised in 2002 and 2008, based on emerging data in the field. A summary of the guidelines for parathyroidectomy in asymptomatic patients is found in Table 1 (65-67). A brief summary of evidence for each guideline follows:

1. Serum calcium $\geq 1 \mathrm{mg} / \mathrm{dL}$ above upper limit of normal: There are no data to support a particular cut point for requiring surgery or safety of follow-up without surgery. Most data demonstrating increased mortality in PHPT come from cohorts with higher levels of serum calcium. Even in the 1 epidemiologic study (Mayo Clinic) showing decreased cardiovascular mortality (RR: 0.6), mortality was increased in those with highest serum calcium levels (quartile serum calcium: $11.2-16.0 \mathrm{mg} / \mathrm{dL}$ ) (50). It seems reasonable though to define a threshold above which surgery would be recommended. The latest workshop on asymptomatic PHPT recommends 1 $\mathrm{mg} / \mathrm{dL}$ above the upper limits of normal.

2. Estimated glomerular filtration rate (EGFR) $<60 \mathrm{~mL} / \mathrm{min}$ : Marked hypercalciuria was initially used as a guideline for surgery even in patients without nephrolithiasis because of concerns about risk of stones and the effect on renal function.

Hypercalciuria is no longer considered an indication for surgery because of poor correlation between urinary calcium excretion and stone formation in the individual patient, as well as poor reproducibility of findings on repeated 24-h collections. The Third International Workshop substituted the presence of stage 3 of chronic kidney disease (creatinine clearance $<60 \mathrm{cc} / \mathrm{min}$ ) as the indication for intervention. There are, however, no data demonstrating worse hyperparathyroidism in mild PHPT using this cut point. The recent data from Walker et al (27) found no difference in PTH (126 vs $123 \mathrm{pg} / \mathrm{mL}$ ) or serum calcium (10.5 vs $10.6 \mathrm{mg} / \mathrm{dL}$ ) in those with EGFR less than vs greater than $60 \mathrm{cc} / \mathrm{min}$. The only other data available suggest that PTH may not rise in PHPT patients until EGFR is below $30 \mathrm{cc} / \mathrm{min}$ (13). As noted previously, data suggest, however, that when the creatinine clearance falls below $60 \mathrm{cc} / \mathrm{min}$, histomorphometric evidence for increased bone resorption can be demonstrated.

3. T-score $\leq-2.5$ or fragility fracture: The initial 1990 guideline suggested intervention for those with greatest evidence of bone reduction at the distal onethird radius, the site most likely to be affected by PHPT. However, strong evidence 
from both long-term observational studies and randomized trials of surgery vs observation in patients with mild PHPT demonstrate a salutary effect of surgical cure on bone density at the lumbar spine and hip, as well as the distal one-third radius (41-43,62-64). These data are particularly striking in those with low bone density at time of diagnosis, with an increase of up to $20 \%$ in lumbar spine BMD reported in those with spine Z-scores < -1.5 (68). Taken together, these data have led to a recommendation for parathyroid surgery in all patients with BMD in the osteoporotic range (T-score $<-2.5$ ) or with a history of osteoporotic fracture.

4. Age younger than $50 \mathrm{yr}$ : Individuals younger than $50 \mathrm{yr}$ are considered to be candidates for parathyroid surgery (Table 1). This indication, present since the first set of guidelines were published in 1990, is still included after an observational study demonstrated that those younger than $50 \mathrm{yr}$ had a significantly higher risk of having progressive disease (as defined by developing a new surgical indication while under observation) than those older than $50 \mathrm{yr}$ (60\% vs 25\%) (69).

There remain some experts who feel that all patients with PHPT regardless of severity should be treated surgically. Indeed, implementation of these guidelines has always depended on conversations between the patient and his or her physician. Given the benefits of surgery, cure of PHPT is never an incorrect approach, if there are no medical contraindications to surgery.

Nonsurgical Patients-The implication underlying the guidelines for surgery in asymptomatic PHPT is that it is safe to observe those who do not meet any of the indications for surgery. Randomized clinical trial data do not demonstrate significant deleterious effects of observation in asymptomatic patients over a short (1-2 yr) period of observation (45-47). No long-term randomized trial data are available, but observational studies report that more than one-third of patients develop new guidelines for surgery if observed for up to $15 \mathrm{yr}$ (64). Stated in another way, however, approx $60 \%$ of subjects followed up for up to $15 \mathrm{yr}$ did not develop any indications for parathyroid surgery. Bone density is stable over the first years of observation but begins to decline particularly at the more cortical hip and forearm sites after 5 more yr of observation.

The Third International Conference on Asymptomatic PHPT issued guidelines for following patients who do not have surgery (Table 2). In addition, patients should be educated to maintain adequate hydration, avoid immobility, and maintain a modest $(1000 \mathrm{mg} / \mathrm{d})$ calcium intake. In a cohort with mild PHPT (but 20\% symptomatic patients), only patients with high 1,25-dihyroxyvitamin D levels had any reason to restrict calcium intake to approx $800 \mathrm{mg} / \mathrm{d}$ (70).

Pharmacologic Therapy-It should be noted that although some studies on medical options for treating PHPT specifically recruited cohorts with mild hypercalcemia, none rigorously limited investigation to patients with asymptomatic disease. Furthermore, there are no drugs currently approved for use specifically in patients with asymptomatic PHPT (71). Estrogen therapy has been known since the 1970s to lower serum calcium levels in post-menopausal women with PHPT (72). The decline is very modest, in the range of 0.5$1.0 \mathrm{mg} / \mathrm{dL}$. Without other reasons for selecting estrogen treatment in a postmenopausal 
women, this option is not recommended. Those who elect hormone replacement therapy for symptoms of menopause, however, can expect an improvement in spine and hip bone density as well (73). The selective estrogen receptor modulator raloxifene has only been studied in a brief randomized controlled trial, in which it too decreased serum calcium levels very modestly, in association with a reduction of bone turnover (74). Bi-sphosphonates (alendronate is the most studied drug in this class) have been shown to improve spine and hip bone density in PHPT without, for the most part, lowering serum calcium levels $(75,76)$. These agents are options for patients with low bone density who do not have surgery. Cinacalcet, a calcimimetic that inhibits parathyroid cell function, has been shown to normalize serum calcium in PHPT (both mild and more severe) for sustained periods (7779). However, the 5-yr data show that although serum calcium continues to be normal, cinacalcet is not associated with improved BMD (79). Currently, cinacalcet is approved for severe PHPT and parathyroid cancer, but it is not approved for use in asymptomatic PHPT.

\section{Conclusion}

Although many questions about asymptomatic PHPT have been answered, many remain. And although the randomized clinical trials offer important and high-quality data on patients with asymptomatic PHPT, it is important to recall that much of the available data from observational studies, even those describing cohorts with mild disease, include both symptomatic and asymptomatic patients.

Asymptomatic PHPT is an entity that was virtually unknown before the 1970s. There are no data on the prevalence of asymptomatic PHPT before that time, although it is highly likely that such patients existed. When asymptomatic PHPT was first identified, it was hypothesized that this was just an earlier recognition of patients who would progress to develop classical PHPT. Instead, observational data over 1-2 decades of follow-up suggest that most patients do not evolve over time to become overtly symptomatic. In most parts of the world, the asymptomatic phenotype of PHPT has replaced classical PHPT.

There are some data that suggest that after an upswing with the recognition of pre-existing cases, the incidence of asymptomatic PHPT may be declining (80,81). Efforts at medical cost containment that have led, in some areas, to more targeted test ordering (and less frequent use of multi-channel screening tests), would be expected to lead to a decline in diagnoses of asymptomatic PHPT. With documented salutary effects of parathyroidectomy, particularly in those patients who meet surgical guidelines, it will be important that this asymptomatic disease continue to be recognized.

\section{Acknowledgments}

Funding source: This work was supported in part by National Institutes of Health grants DK074457, DK084986, and DK32333.

\section{References}

1. Albright F, Aub JC, Bauer W. Hyperparathyroidism: a common and polymorphic condition as illustrated by seventeen proved cases from one clinic. JAMA. 1934; 102:1276-1287. 
2. Heath H, Hodgson SF, Kennedy MA. Primary hyperparathyroidism: incidence, morbidity, and economic impact in a community. N Engl J Med. 1980; 302:189-193. [PubMed: 7350459]

3. Silverberg SJ, Bilezikian JP. The diagnosis and management of asymptomatic primary hyperparathyroidism. Nat Clin Pract Endocrinol Metab. 2006; 2(9):494-503. [PubMed: 16957763]

4. Eastell R, Arnold A, Brandi ML, et al. Diagnosis of asymptomatic primary hyperparathyroidism: Proceedings of the Third International Workshop. J Clin Endocrinol Metab. 2009; 94(2):340-350. [PubMed: 19193909]

5. Bilezikian, JP.; Mulder, JE.; Silverberg, SJ. Hypercalcemic states: differential diagnosis and acute management. In: Coe, FL.; Favus, MJ., editors. Disorders of Bone and Mineral Metabolism. 2. Philadelphia, PA: Lippincott, Williams \& Wilkins; 2008.

6. Fuleihan, Gel-H. Familial benign hypocalciuric hypercalcemia. J Bone Miner Res. 2002; 17(Suppl 2):N51-N56. [PubMed: 12412778]

7. Endres DB, Villanueva R, Sharp CF Jr, Singer FR. Immunochemiluminometric and immunoradiometric determinations of intact and total immunoreactive parathyrin: performance in the differential diagnosis of hypercalcemia and hypoparathyroidism. Clin Chem. 1991; 37:162-168. [PubMed: 1993319]

8. Nussbaum SR, Zahradnik RJ, Lavigne JR, et al. Highly sensitive two-site immunoradiometric assay of parathyrin, and its clinical utility in evaluating patients with hypercalcemia. Clin Chem. 1987; 33:1364-1367. [PubMed: 3608153]

9. Silverberg SJ, Brown I, LoGerfo P, et al. Clinical utility of an immunoradiometric assay for whole PTH (1-84) in primary hyperparathyroidism. J Clin Endocrinol Metab. 2003; 88(10):4725-4730. [PubMed: 14557447]

10. Silverberg SJ, Lewiecki EM, Mosekilde L, et al. Presentation of asymptomatic primary hyperparathyroidism: proceedings of the Third International Workshop. J Clin Endocrinol Metab. 2009; 94:351-365. [PubMed: 19193910]

11. Bilezikian JP, Silverberg SJ. Clinical practice: asymptomatic primary hyperparathyroidism. N Engl J Med. 2004; 350(17):1746-1751. [PubMed: 15103001]

12. Silverberg SJ, Shane E, Dempster DW, Bilezikian JP. The effects of vitamin D insufficiency in patients with primary hyperparathyroidism. Am J Med. 1999; 107(6):561-567. [PubMed: 10625024]

13. Boudou P, Ibrahim F, Cormier C, et al. A very high incidence of low 25 hydroxy-vitamin D serum concentration in a French population of patients with primary hyperparathyroidism. J Endocrinol Invest. 2006; 29(6):511-515. [PubMed: 16840828]

14. Broadus AE, Horst RL, Lang R, et al. The importance of circulating 1,25-dihydroxyvitamin D in the pathogenesis of hypercalciuria and renal-stone formation in primary hyperparathyroidism. $\mathrm{N}$ Engl J Med. 1980; 302:421-426. [PubMed: 7351950]

15. Silverberg SJ, Shane E, de la Cruz L, et al. Skeletal disease in primary hyperparathyroidism. J Bone Miner Res. 1989; 4(3):283-291. [PubMed: 2763869]

16. Eriksen EF. Primary hyperparathyroidism: lessons from bone histomorphometry. J Bone Miner Res. 2002; 17(Suppl 2):N95-N97. [PubMed: 12412784]

17. Dempster DW, Muller R, Zhou H, et al. Preserved three-dimensional cancellous bone structure in mild primary hyperparathyroidism. Bone. 2007; 41(1):19-24. [PubMed: 17490921]

18. Stein EM, Dempster DW, Udesky J, et al. Vitamin D deficiency influences histomorphometric features of bone in primary hyperparathyroidism. Bone. 2011; 48(3):557-561. [PubMed: 20950725]

19. Dauphine RT, Riggs BL, Scholz DA. Back pain and vertebral crush fractures: an unemphasized mode of presentation for primary hyperparathyroidism. Ann Intern Med. 1975; 83:365-367. [PubMed: 126654]

20. Wilson RJ, Rao S, Ellis B, et al. Mild asymptomatic primary hyperparathyroidism is not a risk factor for vertebral fractures. Ann Intern Med. 1988; 109:959-962. [PubMed: 3195878]

21. Larsson K, Ljunghall S, Krusemo UB, et al. The risk of hip fractures in patients with primary hyperparathyroidism: a population-based cohort study with a follow-up of 19 years. J Intern Med. 1993; 234:585-593. [PubMed: 8258750] 
22. Kenny AM, MacGillivray DC, Pilbeam CC, et al. Fracture incidence in postmenopausal women with primary hyperparathyroidism. Surgery. 1995; 118:109-114. [PubMed: 7604371]

23. Khosla S, Melton LJ, Wermers RA, et al. Primary hyperparathyroidism and the risk of fracture: a population-based study. J Bone Miner Res. 1999; 14:1700-1707. [PubMed: 10491217]

24. Vignali E, Viccica G, Diacinti D, et al. Morphometric vertebral fractures in postmenopausal women with primary hyperparathyroidism. J Clin Endocrinol Metab. 2009; 94(7):2306-2312. [PubMed: 19401378]

25. Vestergaard P, Mollerup CL, Frøkjaer VG, et al. Cohort study of risk of fracture before and after surgery for primary hyperparathyroidism. BMJ. 2000; 321:598-602. [PubMed: 10977834]

26. Khosla S, Melton J 3rd. Fracture risk in primary hyperparathyroidism. J Bone Miner Res. 2002; 17(Suppl 2):N103-N107. [PubMed: 12412786]

27. Walker MD, Dempster DW, McMahon DJ, et al. Effect of renal function on skeletal health in primary hyperparathyroidism. J Clin Endocrinol Metab. 2012; 97(5):1501-1507. [PubMed: 22399521]

28. Patten BM, Bilezikian JP, Mallette LE, et al. Neuromuscular disease in primary hyperparathyroidism. Ann Intern Med. 1974; 80:182-193. [PubMed: 4811792]

29. Turken SA, Cafferty M, Silverberg SJ, et al. Neuromuscular involvement in mild, asymptomatic primary hyperparathyroidism. Am J Med. 1989; 87:553-557. [PubMed: 2816971]

30. Silverberg SJ, Walker MD, Bilezikian JP. Asymptomatic primary hyperparathyroidism. J Clin Densitom. 2013; 16:14-21. [PubMed: 23374736]

31. Prager G, Kalaschek A, Kaczirek K, et al. Parathyroidectomy improves concentration and retentiveness in patients with primary hyperparathyroidism. Surgery. 2002; 132(6):930-935. [PubMed: 12490838]

32. Roman SA, Sosa JA, Mayes L, et al. Parathyroidectomy improves neurocognitive deficits in patients with primary hyperparathyroidism. Surgery. 2005; 138(6):1121-1128. [PubMed: 16360399]

33. Chiang CY, Andrewes DG, Anderson D, et al. A controlled, prospective study of neuropsychological outcomes post parathyroidectomy in primary hyperparathyroid patients. Clin Endocrinol (Oxf). 2005; 62(1):99-104. [PubMed: 15638877]

34. Benge JF, Perrier ND, Massman PJ, et al. Cognitive and affective sequelae of primary hyperparathyroidism and early response to parathyroidectomy. J Int Neuropsychol Soc. 2009; 15(6):1002-1011. [PubMed: 19807940]

35. Walker MD, McMahon DJ, Inabnet WB, et al. Neuropsychological features in primary hyperparathyroidism: a prospective study. J Clin Endocrinol Metab. 2009; 94(6):1951-1958. [PubMed: 19336505]

36. Roman SA, Sosa JA, Pietrzak RH, et al. The effects of serum calcium and parathyroid hormone changes on psychological and cognitive function in patients undergoing parathyroidectomy for primary hyperparathyroidism. Ann Surg. 2011; 253(1):131-137. [PubMed: 21233611]

37. Perrier ND, Balachandran D, Wefel JS, et al. Prospective, randomized, controlled trial of parathyroidectomy versus observation in patients with "asymptomatic" primary hyperparathyroidism. Surgery. 2009; 146(6):1116-1122. [PubMed: 19879613]

38. Brown GG, Preisman RC, Kleerekoper M. Neurobehavioral symptoms in mild primary hyperparathyroidism: related to hypercalcemia but not improved by parathyroidectomy. Henry Ford Hosp Med J. 1987; 35(4):211-215. [PubMed: 3329170]

39. Solomon BL, Schaaf M, Smallridge RC. Psychologic symptoms before and after parathyroid surgery. Am J Med. 1994; 96(2):101-106. [PubMed: 8109593]

40. Espiritu RP, Kearns AE, Vickers KS. Depression in primary hyperparathyroidism: prevalence and benefit of surgery. J Clin Endocrinol Metab. 2011; 96(11):E1737-E1745. [PubMed: 21917870]

41. Pasieka JL, Parsons LL, Demeure MJ, et al. Patient-based surgical outcome tool demonstrating alleviation of symptoms following parathyroidectomy in patients with primary hyperparathyroidism. World J Surg. 2002; 26(8):942-949. [PubMed: 12016473]

42. Sheldon DG, Lee FT, Neil NJ, Ryan JA Jr. Surgical treatment of hyperparathyroidism improves health-related quality of life. Arch Surg. 2002; 137(9):1022-1026. discussion 1026-1028.

[PubMed: 12215152] 
43. Quiros RM, Alef MJ, Wilhelm SM, et al. Health-related quality of life in hyperparathyroidism measurably improves after parathyroidectomy. Surgery. 2003; 134(4):675-681. discussion 681683. [PubMed: 14605629]

44. Amstrup AK, Rejnmark L, Mosekilde L. Patients with surgically cured primary hyperparathyroidism have a reduced quality of life compared with population-based healthy sex-, age-, and season-matched controls. Eur J Endocrinol. 2011; 165(5):753-760. [PubMed: 21862666]

45. Rao DS, Phillips ER, Divine GW, Talpos GB. Randomized controlled clinical trial of surgery versus no surgery in patients with mild asymptomatic primary hyperparathyroidism. J Clin Endocrinol Metab. 2004; 89(11):5415-5422. [PubMed: 15531491]

46. Bollerslev J, Jansson S, Mollerup CL, et al. Medical observation, compared with parathyroidectomy, for asymptomatic primary hyperparathyroidism: a prospective, randomized trial. J Clin Endocrinol Metab. 2007; 92(5):1687-1692. [PubMed: 17284629]

47. Ambrogini E, Cetani F, Cianferotti L, et al. Surgery or surveillance for mild asymptomatic primary hyperparathyroidism: a prospective, randomized clinical trial. J Clin Endocrinol Metab. 2007; 92(8):3114-3121. [PubMed: 17535997]

48. Nilsson IL, Yin L, Lundgren E, et al. Clinical presentation of primary hyperparathyroidism in Europe-nationwide cohort analysis on mortality from nonmalignant causes. J Bone Miner Res. 2002; 17(Suppl 2):N68-N74. [PubMed: 12412780]

49. Ogard CG, Engholm G, Almdal TP, Vestergaard H. Increased mortality in patients hospitalized with primary hyperparathyroidism during the period 1977-1993 in Denmark. World J Surg. 2004; 28(1):108-111. [PubMed: 14648050]

50. Wermers RA, Khosla S, Atkinson EJ, et al. Survival after the diagnosis of hyperparathyroidism: a population-based study. Am J Med. 1998; 104(2):115-122. [PubMed: 9528728]

51. Bollerslev J, Rosen T, Mollerup CL, et al. Effect of surgery on cardiovascular risk factors in mild primary hyperparathyroidism. J Clin Endocrinol Metab. 2009; 94(7):2255-2261. [PubMed: 19351725]

52. Rubin MR, Maurer MS, McMahon DJ, et al. Arterial stiffness in mild primary hyperparathyroidism. J Clin Endocrinol Metab. 2005; 90(6):3326-3330. [PubMed: 15769995]

53. Walker MD, Fleischer J, Rundek T, et al. Carotid vascular abnormalities in primary hyperparathyroidism. J Clin Endocrinol Metab. 2009; 94(10):3849-3856. [PubMed: 19755478]

54. Walker MD, Fleischer JB, Di Tullio MR, et al. Cardiac structure and diastolic function in mild primary hyperparathyroidism. J Clin Endocrinol Metab. 2010; 95(5):2172-2179. [PubMed: 20228165]

55. Iwata S, Walker MD, Di Tullio MR, et al. Aortic valve calcification in mild primary hyperparathyroidism. J Clin Endocrinol Metab. 2012; 97(1):132-137. [PubMed: 22031523]

56. Walker MD, Rundek T, Homma S, et al. Effect of parathyroidectomy on subclinical cardiovascular disease in mild primary hyperparathyroidism. Eur J Endocrinol. 2012; 167(2):277-285. [PubMed: 22660025]

57. Khoo TK, Vege SS, Abu-Lebdeh HS, et al. Acute pancreatitis in primary hyperparathyroidism: a population-based study. J Clin Endocrinol Metab. 2009; 94(6):2115-2118. [PubMed: 19318456]

58. Fitzpatrick LA, Bilezikian JP. Acute primary hyperparathyroidism. Am J Med. 1987; 82:275-282. [PubMed: 3812520]

59. Cusano NE, Silverberg SJ, Bilezikian JP. Normocalcemic primary hyperparathyroidism. J Clin Densitom. 2013; 16:33-39. [PubMed: 23374739]

60. Dowthwaite SA, Young JE, Pasternak JD, Yoo J. Surgical management of primary hyperparathyroidism. J Clin Densitom. 2013; 16:48-53. [PubMed: 23374741]

61. Udelsman BV, Udelsman R. Surgery in primary hyperparathyroidism: extensive personal experience. J Clin Densitom. 2013; 16:54-59. [PubMed: 23374742]

62. Rao DS, Wilson RJ, Kleerekoper M, Parfitt AM. Lack of biochemical progression or continuation of accelerated bone loss in mild asymptomatic primary hyperparathyroidism. J Clin Endocrinol Metab. 1988; 67:1294-1298. [PubMed: 3192682]

63. Silverberg SJ, Shane E, Jacobs TP, et al. A 10-year prospective study of primary hyperparathyroidism with or without parathyroid surgery. N Engl J Med. 1999; 341:1249-1255. [PubMed: 10528034] 
64. Rubin MR, Bilezikian JP, McMahon DJ, et al. The natural history of primary hyperparathyroidism with or without parathyroid surgery after 15 years. J Clin Endocrinol Metab. 2008; 93(9):34623470. [PubMed: 18544625]

65. National Institutes of Health. Consensus development conference statement on primary hyperparathyroidism. J Bone Miner Res. 1991; 6(Suppl 2):S9-S13. [PubMed: 1763674]

66. Bilezikian JP, Potts JT Jr, Fuleihan Gel-H, et al. Summary statement from a workshop on asymptomatic primary hyperparathyroidism: a perspective for the 21 st century. J Bone Miner Res. 2002; 17(Suppl 2):N2-N11. [PubMed: 12412771] J Clin Endocrinol Metab. 87:5353-5361. [PubMed: 12466320]

67. Bilezikian, JP.; Khan, AA.; Potts, JT, Jr. 2009 Guidelines for the management of asymptomatic primary hyperparathyroidism: Summary Statement from the Third International Workshop. J Clin Endocrinol Metab; Third International Workshop on the Management of Asymptomatic Primary Hyperthyroidism; p. 335-339.

68. Silverberg SJ, Locker FG, Bilezikian JP. Vertebral osteopenia: a new indication for surgery in primary hyperparathyroidism. J Clin Endocrinol Metab. 1996; 81(11):4007-4012. [PubMed: 8923852]

69. Silverberg SJ, Brown I, Bilezikian JP. Age as a criterion for surgery in primary hyperparathyroidism. Am J Med. 2002; 113(8):681-684. [PubMed: 12505119]

70. Locker FG, Silverberg SJ, Bilezikian JP. Optimal dietary calcium intake in primary hyperparathyroidism. Am J Med. 1997; 102(6):543-550. [PubMed: 9217669]

71. Khan A, Grey A, Shoback D. Medical management of asymptomatic primary hyperparathyroidism: Proceedings of the Third International Workshop. J Clin Endocrinol Metab. 2009; 94:373-381. [PubMed: 19193912]

72. Marcus R, Madvig P, Crim M, et al. Conjugated estrogens in the treatment of postmenopausal women with hyperparathyroidism. Ann Intern Med. 1984; 100:633-640. [PubMed: 6324624]

73. Grey AB, Stapleton JP, Evans MC, et al. Effect of hormone replacement therapy on BMD in postmenopausal women with primary hyperparathyroidism. Ann Intern Med. 1996; 125:360-368. [PubMed: 8702086]

74. Rubin MR, Lee K, Silverberg SJ. Raloxifene lowers serum calcium and markers of bone turnover in primary hyperparathyroidism. J Clin Endocrinol Metab. 2003; 88(3):1174-1178. [PubMed: 12629102]

75. Kahn AA, Bilezikian JP, Kung A, et al. Alendronate in primary hyperparathyroidism: a doubleblind, randomized, placebo-controlled trial. J Clin Endocrinol Metab. 2004; 89(7):3319-3325. [PubMed: 15240609]

76. Chow CC, Chan WB, Li JKY, et al. Oral alendronate increases bone mineral density in postmenopausal women with primary hyperparathyroidism. J Clin Endocrinol Metab. 2003; 88(2): 581-587. [PubMed: 12574184]

77. Peacock M, Bilezikian JP, Klassen P, et al. Cinacalcet hydrochloride maintains long-term normocalcemia in patients with primary hyperparathyroidism. J Clin Endocrinol Metab. 2005; 90(1):135-141. [PubMed: 15522938]

78. Peacock M, Bolognese MA, Borofsky M, et al. Cinacalcet treatment of primary hyperparathyroidism: biochemical and bone densitometric outcomes in a five-year study. J Clin Endocrinol Metab. 2009; 94:4860-4867. [PubMed: 19837909]

79. Peacock M, Bilezikian JP, Bolognese MA, et al. Cinacalcet $\mathrm{HCl}$ reduces hypercalcemia in primary hyperparathyroidism across a wide spectrum of disease severity. J Clin Endocrinol Metab. 2011; 96(1):E9-E18. [PubMed: 20943783]

80. Wermers RA, Khosla S, Atkinson EJ, et al. The rise and fall of primary hyperparathyroidism: a population-based study in Rochester, Minnesota, 1965-1992. Ann Intern Med. 1997; 126(6):433440. [PubMed: 9072928]

81. Wermers RA, Khosla S, Atkinson EJ, et al. Incidence of primary hyperparathyroidism in Rochester, Minnesota, 1993-2001: an update on the changing epidemiology of the disease. J Bone Miner Res. 2006; 21(1):171-177. [PubMed: 16355286] 
Table 1

Guidelines for Parathyroidectomy in Asymptomatic Primary Hyperparathyroidism

\begin{tabular}{|c|c|c|c|}
\hline Guideline & 1990 & 2002 & 2009 \\
\hline $\begin{array}{l}\text { Serum calcium (elevation above normal; } \\
\mathrm{mg} / \mathrm{dL} \text { ) }\end{array}$ & 1.6 & 1.0 & 1.0 \\
\hline 24-h urinary calcium & $>400 \mathrm{mg}$ & $>400 \mathrm{mg}$ & No longer used \\
\hline Creatinine clearance $\mathrm{cc} / \mathrm{min}$ & Reduced by $30 \%$ & Reduced by $30 \%$ & $<60 \mathrm{cc} / \mathrm{min}$ per $1.73 \mathrm{~m}^{2}$ \\
\hline Bone mineral density (site) & Z-score $<-2.0$ (forearm) & $\mathrm{T}$-score $\leq-2.5$ (any site) & $\begin{array}{l}\text { T-score } \leq-2.5 \text { or fragility fracture } \\
\text { (any site) }\end{array}$ \\
\hline Age (yr) & $<50$ & $<50$ & $<50$ \\
\hline
\end{tabular}


Table 2

Guidelines for Follow-Up of Patients With Asymptomatic Primary Hyperparathyroidism Who Do Not Undergo Parathyroidectomy

\begin{tabular}{lll}
\hline Guideline & $\mathbf{2 0 0 2}^{\boldsymbol{a}}$ & $\mathbf{2 0 0 9}^{\boldsymbol{b}}$ \\
\hline Serum calcium & Semiannual & Annual \\
24-h urinary calcium & Annual & Not recommended \\
Creatinine clearance & Annual & Not recommended \\
Serum creatinine & Annual & $\begin{array}{l}\text { Annual } \\
\text { Calculation of glomerular filtration rate }\end{array}$ \\
Bone density & Annual & Annual or biannual \\
Abdominal X-ray & Not recommended & Not recommended \\
\hline
\end{tabular}

${ }^{a}$ Adapted from Ref. (66).

${ }^{b}$ Adapted from Ref. (67). 